\title{
Pharmacoepidemiology of testosterone prescribing in Australia, 1992-2010
}

\section{David J Handelsman MB BS, FRACP, PhD, Director \\ ANZAC Research Institute, University of Sydney, Sydney, NSW. \\ djh@anzac.edu.au}

MJA 2012; 196: 642-645 doi: 10.5694/mjall.11277 ince the Nobel Prize-winning characterisation of testosterone as the mammalian androgen responsible for male reproductive function and virilisation in $1935,^{1-3}$ and its introduction into clinical practice 2 years later, ${ }^{4}$ the only unequivocal indication for prescribing testosterone has been physiological androgen replacement therapy for men with androgen deficiency due to pathological disorders of the hypothalamic-pituitary-testicular axis. $^{5}$

A previous study of testosterone prescribing in Australia during the 1990s, which used Pharmaceutical Benefits Scheme (PBS) data, showed a gradual increase in testosterone prescribing over the decade consistent with population growth. It also showed striking disparities between states and territories, as well as two upsurges that were driven by promotional activity and partially curtailed by regulatory restraint. ${ }^{6}$ The present study updates the surveillance of national testosterone prescribing by a further decade and incorporates an independent source of commercial pharmaceutical sales data.

\section{Methods}

PBS data (including the Repatriation Pharmaceutical Benefits Scheme) on all testosterone products were obtained from the Medicare Australia website. Available data included numbers of units prescribed and expenditure for each state and territory, and for each testosterone product, by month from January 1992 to December 2010. No health or anthropometric information on the people who filled the prescriptions was available.

To compare dosing regimens of different testosterone products, the prescription unit of each product was converted into defined monthly doses (ie, the number of months covered by one prescription unit) (Box 1), based on the average dose

\begin{abstract}
Objective: To describe patterns of testosterone prescribing in Australia over the past two decades by state or territory and by product type.

Design and setting: Observational analysis of testosterone prescribing data obtained from two independent data sources - the Pharmaceutical Benefits Scheme (PBS) and IMS, a source of commercial pharmaceutical sales data.

Main outcome measures: Temporal trends in testosterone prescribing measured as units prescribed (converted into monthly defined doses) and expenditure - according to state or territory and product type (injectable, implantable, transdermal and oral).

Results: Over two decades, total annual expenditure on testosterone products increased ninefold to $\$ 12.7$ million according to PBS data and fivefold to $\$ 16.3$ million according to IMS data. When adjusted for inflation and population growth, expenditure increased 4.5-fold according to PBS data and 2.5-fold according to IMS data. The patterns of testosterone prescribing according to PBS and IMS data were highly congruent. When converted into monthly defined dose units, testosterone prescribing increased over the two decades with approximately twofold differences in total testosterone prescribed per capita between the states and territories with the highest and lowest rates of prescribing. When analysed by product type, the stable market patterns over the first 15 years were disrupted by sharp changes to create market dominance owing to introduction of two new testosterone products - a depot injectable testosterone and a transdermal testosterone gel.

Conclusions: The progressive increase in PBS-subsidised testosterone prescribing without changes in proven medical indications or improvements in diagnosis of pathologically based androgen deficiency are likely to be due to promotion-driven non-compliance with PBS prescribing criteria, indicating that more effective implementation of the criteria is needed.
\end{abstract}

registered for use in adults (obtained from the approved product information) and consistent with the conventional definition of standardised dosing (WHO Collaborating Centre for Drug Statistics Methodology, http://www.whocc.no). Expenditure data were adjusted for inflation, according to the consumer price index, by using the Reserve Bank of Australia inflation calculator (http:// www.rba.gov.au/calculator).

Testosterone prescribing data were also obtained from IMS - a company that provides national sales data by year by pooling data from the Australian Pharmaceutical Index and the Australian Hospital Index (http://www.imshealth.com/portal/ site/ims). For each testosterone product, it provided the number of units prescribed and expenditure for each year (1993 to 2010, inclusive), but not monthly or state- and territory-based data. IMS data include PBS-subsidised prescribing, private (non-PBS) prescribing and hospitalbased prescribing.

\section{Results}

Annual expenditure on testosterone products increased 9.1-fold according to PBS data (from about $\$ 1.4$ million to $\$ 12.7$ million, 1992 to 2010) and 5.3-fold according to IMS data (from about $\$ 3.1$ million to $\$ 16.3$ million, 1993 to 2010) (Box 2). When adjusted for inflation $(60 \%)$ and population increase $(28 \%)$ over the same period, expenditure increased about 4.5 -fold according to PBS data and 2.5-fold according to IMS data (data not shown). PBS expenditure data were consistently lower than IMS expenditure data; the proportion increased over the two decades of observation - from $60 \%$ to $75 \%$, with a sharp rise from 2005 (data not shown). According to IMS data, over $90 \%$ of testosterone prescribing was through pharmacies during the 1990s; there was a sharp rise in hospital-based prescribing between 2000 and 2005, such that pharmacy-based prescribing reached a nadir of $75 \%$ in 2005 . Pharmacy-based prescribing then rose to over $97 \%$ by 2010 (data not shown). 
When viewed as total testosterone prescribed in monthly defined dose units, testosterone prescribing increased over the two decades with consistent parallelism between the two data sources (Box 2). For both data sources, there was a strikingly steeper rise in cost relative to dose from 2005 onwards. According to the PBS data, there was a greater increase in expenditure (4.5-fold [adjusted for inflation]) than in total prescribing (2.5-fold).

When testosterone prescribing was analysed by state and territory, there was a 2.1-fold difference between the states and territories with the highest and lowest rates of prescribing in 1992 (New South Wales v Western Australia and Tasmania) and a 2.2fold difference in 2010 (Queensland v Tasmania) (Box 3; PBS data only). Over the two decades of observation, testosterone prescribing increased in all states and territories, with the increase ranging from 1.5-fold (New South Wales) to 4.3-fold (Western Australia).

When expenditure was analysed according to product type, the patterns in both data sources were highly congruent (Box 4). Expenditure on short-acting injectable testosterone was stable and declined slightly after 2006, when the long-acting injectable testosterone became available on the PBS. Expenditure on the long-acting injectable product rose steeply from 2006. Expenditure on implantable testosterone increased gradually from its introduction to the PBS in 1996, peaked in 2005, and fell after longacting injectable testosterone became available on the PBS.

Transdermal testosterone products were introduced to the PBS in 2000 as patches, but prescribing of transdermal products increased sharply from 2006, when a testosterone gel product became available and the use of transdermal patches declined modestly (data not shown). Oral testosterone prescribing rates were stable over the two decades.

\section{Discussion}

Over the past two decades, testosterone prescribing in Australia has progressively increased, predominantly via community pharmacies and even

\section{Testosterone products on the PBS}

\begin{tabular}{|c|c|c|c|c|}
\hline Generic name & Brand name; formulation (PBS item code) & $\begin{array}{l}\text { Prescription } \\
\text { unit }\end{array}$ & $\begin{array}{l}\text { Months } \\
\text { covered* }\end{array}$ & $\begin{array}{l}\text { Cost per } \\
\text { month }\end{array}$ \\
\hline \multicolumn{5}{|l|}{ Injectable } \\
\hline Testosterone enanthate & Primoteston; 250 mg/1 mL oil (2114G) & 3 vials & 2 & $\$ 22$ \\
\hline Mixed testosterone esters & Sustanon; 250 mg/1 mL oil (2101N) & 3 vials & 2 & $\$ 22$ \\
\hline Testosterone undecanoate & Reandron; $1000 \mathrm{mg} / 4 \mathrm{~mL}$ oil (9004X) & 1 vial & 3 & $\$ 49$ \\
\hline \multicolumn{5}{|l|}{ Implantable } \\
\hline Testosterone & $\begin{array}{l}\text { Testosterone implant; } 100 \mathrm{mg} \text { (8098F) or } 200 \mathrm{mg} \\
\text { (8099G) }\end{array}$ & 1 implant & 1 & $\$ 210$ \\
\hline \multicolumn{5}{|l|}{ Transdermal } \\
\hline Testosterone patch & Androderm; 2.5 mg (8460G) & 60 patches & 2 & $\$ 96$ \\
\hline Testosterone patch & Androderm; 5 mg (8619P) & 30 patches & 1 & $\$ 96$ \\
\hline Testosterone gel & Testogel; 50 mg (8830R) & 30 sachets & 1 & $\$ 95$ \\
\hline \multicolumn{5}{|l|}{ Oral } \\
\hline Testosterone undecanoate & Andriol; $40 \mathrm{mg}$ capsules $(2115 \mathrm{H})$ & 60 capsules & 0.5 & $\$ 75$ \\
\hline
\end{tabular}

after adjustment for inflation and population growth. There was a greater increase in expenditure than in total prescribing because of substitution of more expensive newer testosterone products for older testosterone products; this is striking for an old, offpatent product in which the active ingredient represents only about $1 \%$ of the marketed product cost. Although the Pharmaceutical Benefits Advisory Committee aims to restrict opportunistic price increases for new products (via reformulation of old drugs) by benchmarking against older products, the range of existing marketed testosterone products provides alternatives that can be used to avoid the lowest cost comparator. However, accepting some price inflation may be an opportunity cost that should be traded off against having newer products available. By contrast, neither oral nor injectable testosterone undecanoate have ever been marketed in the United States, thereby restricting prescribing options.

The reason for the striking differences in testosterone prescribing between states and territories is not clear. The market profile of testosterone products was stable over most of the study period, until sharp changes from 2006, when two new products (a long-acting injectable product and a transdermal gel) with associated promotion, quickly dominated the testosterone market. Among the depot products, patients have been shown to prefer the 3-monthly injectable product over the 6-monthly implantable product in a direct crossover study. ${ }^{7}$ Among the daily dosing products, patient preferences for gel over transdermal patches is supported by less direct (non-crossover) clinical trials. $^{8-11}$ Introduction of the long-acting injectable testosterone reduced use of

\section{National expenditure and defined monthly doses for testosterone products, according to PBS and IMS data,} 1992-2010
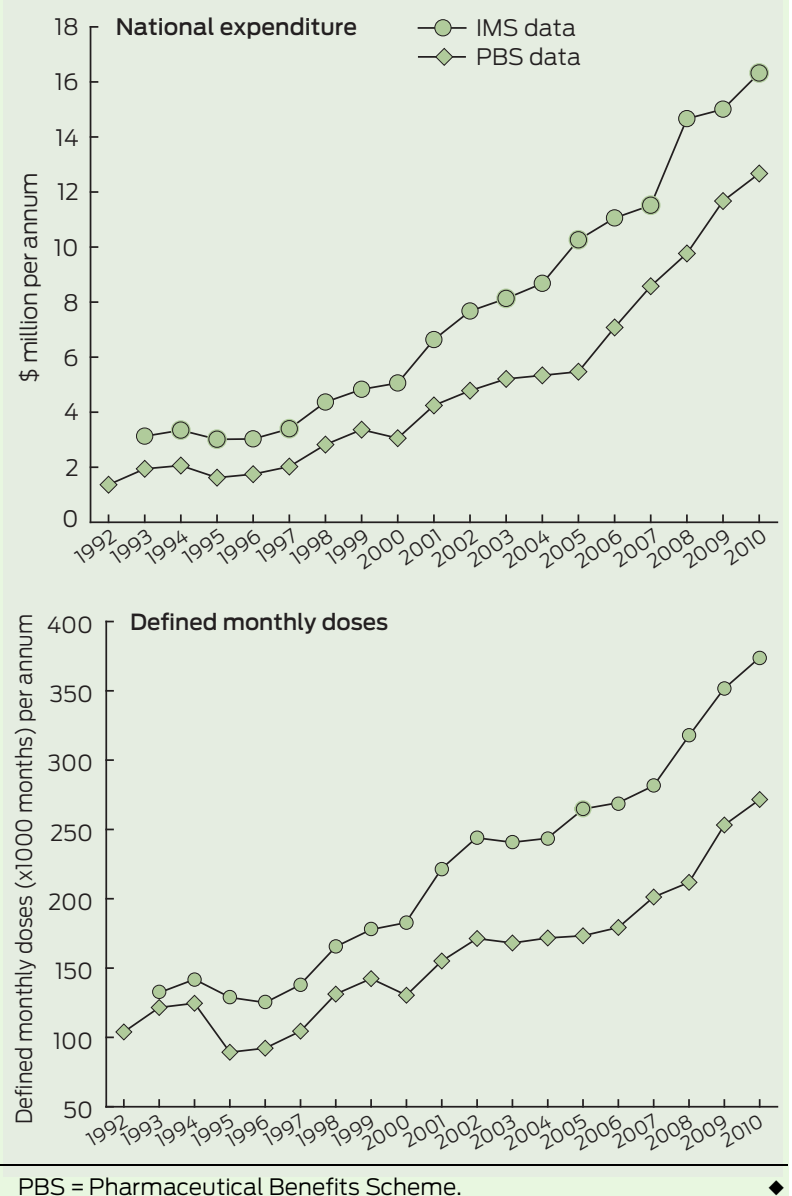
3 Defined monthly doses of testosterone products by state and territory, according to PBS data, 1992-2010

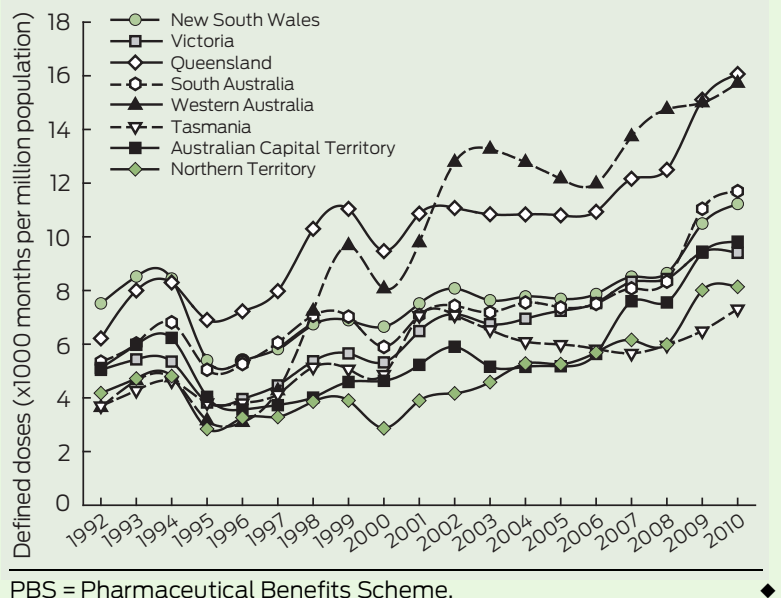

PBS = Pharmaceutical Benefits Scheme.

4 National expenditure on testosterone products by product type, according to PBS and IMS data, 1992-2010*
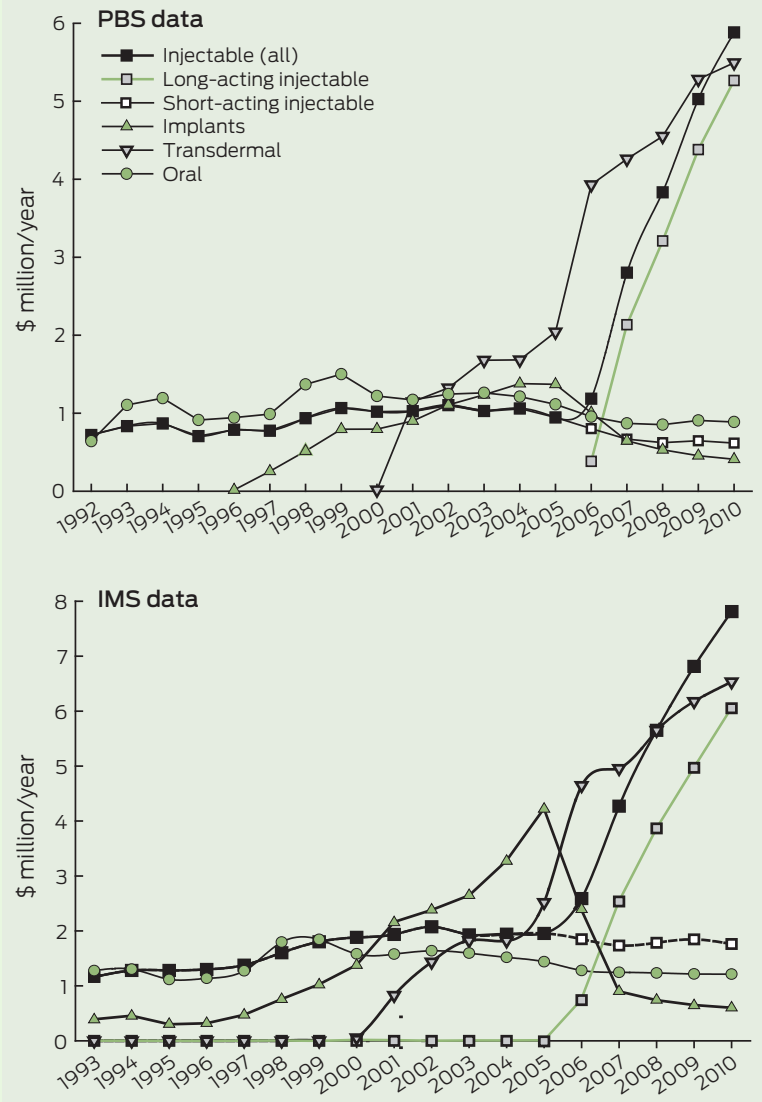

PBS = Pharmaceutical Benefits Scheme. * The "Injectable (all)" category includes long- and short-acting injectable products and the "Transdermal" category includes patches and gel.

implantable testosterone but had little effect on use of short-acting injectable testosterone products. Similarly, introduction of the testosterone gel modestly reduced use of transdermal patch testosterone without affecting use of the oral testosterone product. However, as both of these popular new testosterone products were marketed by the same company, the market for testosterone products was transformed from a competitive duopoly into a market dominated by one company, with its market share increasing from $63 \%$ in 2006 to $83 \%$ in 2009.

Given the prevailing eligibility criteria, the substantial increases in PBSsubsidised testosterone prescribing must reflect either improved diagnosis of androgen deficiency, consistent with the eligibility criteria, or increasing evasion of the criteria. It is well established that, even in countries with effective national health systems that provide universal access to health care, most men with Klinefelter syndrome (the most common pathological cause of androgen deficiency) are never diagnosed during their lifetime. ${ }^{12,13}$ Hence improved diagnosis of Klinefelter syndrome might increase testosterone prescribing. However, there is no suggestion or evidence of such improvement, 6,13 and the increase in testosterone prescribing could not be explained solely by increased diagnosis of Klinefelter syndrome. A more plausible explanation is the promotion of testosterone prescribing driven opportunistically by new product launches for speculative, non-approved indications such as "andropause" and male sexual dysfunction. It remains paradoxical that concurrent with underdiagnosis and undertreatment of genuine androgen deficiency, there is growing overuse of testosterone in older men as an antiageing tonic and non-specific treatment for sexual dysfunction, for which sound evidence is lacking. Although it cannot be excluded that, in the future, pharmacological testosterone treatment might prove effective and safe in such non-androgen deficiency conditions, ${ }^{14}$ in the interim, it is highly marketable with an easily confected popularity which creates a demand that bypasses sound clinical practice.

In 2000, the first national guidelines for testosterone prescribing in Australia were developed by the Endocrine Society of Australia, ${ }^{15}$ and these have remained the eligibility criteria for PBS-subsidised testoster- one prescribing. The guidelines support legitimate testosterone prescribing for pathologically based androgen deficiency and deter prescribing for unproven use of testosterone. Crucially, they distinguish pathologically based androgen deficiency from other speculative indications (notably male ageing) that lack a pathological basis or evidence of testosterone safety and effectiveness. ${ }^{14}$ However, testosterone prescribing for andropause has been encouraged by North American guidelines published in $2006^{16}$ and European-based guidelines published in $2005,{ }^{17}$ both of which have been recently republished without significant changes. ${ }^{18,19}$ These differ from the Australian guidelines by blurring the key distinction between pathologically based androgen deficiency and andropause, providing more lax criteria (eg, higher blood testosterone thresholds, encouragement of testosterone treatment trials and use of inaccurate "free" testosterone calculations) and lacking regulatory enforcement. More recent attempts to define andropause into existence ${ }^{20}$ have been criticised on the basis of flawed analysis of observational data, ${ }^{21}$ and the cardiovascular risks of prescribing testosterone treatment for older men have been highlighted. ${ }^{22}$ Similarly, there has been increasing advocacy of testosterone treatment for male sexual dysfunction during the past decade ${ }^{23}$ despite androgen deficiency being a rare cause of primary presentation with male sexual dysfunction. ${ }^{24}$

The striking congruence between the IMS and PBS data is an important finding. The two data sources provide useful, complementary perspectives on testosterone prescribing despite the fact that only the IMS data include private and hospital-based prescribing. Neither database includes sales of testosterone by compounding chemists in costly products with untested pharmacological efficacy. The PBS provides an attractive subsidy for testosterone prescribing within approved guidelines, which makes testosterone prescribing for unapproved uses at full market cost unattractive. The success of this approach to subsidising testosterone depends on development of best-practice guidelines and compliance with prescribing criteria. Yet, 
levels of compliance with PBS prescribing criteria are not known and mounting evidence suggests possible disregard for the criteria, especially for andropause and male sexual dysfunction. This highlights the need to consider more cost-effective implementation of the PBS prescribing criteria.

Acknowledgements: I am grateful to Chris Proctor and Nicole Sweetman (IMS) for providing access to IMS data and to Lam Ly for assisting with the data analysis.

Competing interests: I have received investigatorinitiated research funding for work not directly related to this study from all companies that have marketed testosterone products in Australia.

Received 4 Oct 2011, accepted 14 Dec 2011.

1 Butenandt A, Hanisch G. [Uber die Umwandlung des Dehydroandrosterons in Androstenol-(17)one-(3) (Testosterone); Umweg zur darstellung des testosterons aus Cholsterin (vorlauf mitteilung)] [German]. Zeischrift Physiologische Chemie 1935; 237: 89-97.

2 David K, Dingmanse E, Freud J, et al. [Uber krystallinisches mannliches Hormon aus Hoden (Testosteron), wirksamer als aus Harn oder aus Cholestrin bereites Androsteron] [German]. Zeischrift Physiologische Chemie 1935; 233: 281-282.

3 Ruzicka L, Wettstein A. [Uber die krystallische Herstellung des Testikelhormons, Testosteron (androsten-3-on-17-ol)] [German]. Helv Chim Acta 1935; 18: 1264-1275.

4 Hamilton JB. Treatment of sexual underdevelopment with synthetic male hormone substance. Endocrinology 1937; 21: 649-654.

5 Handelsman DJ. Androgen physiology, pharmacology and abuse. In: DeGroot LJ, Jameson JL, editors. Endocrinology. 6th ed.
Philadelphia: Elsevier Saunders, 2010: 2469 2498.

6 Handelsman DJ. Trends and regional differences in testosterone prescribing in Australia, 19912001. Med J Aust 2004; 181: 419-422.

7 Fennell C, Sartorius G, Ly LP, et al. Randomized cross-over clinical trial of injectable vs. implantable depot testosterone for maintenance of testosterone replacement therapy in androgen deficient men. Clin Endocrinol (Oxf) 2010; 73 : 102-109.

8 Steidle C, Schwartz S, Jacoby K, et al. AA2500 testosterone gel normalizes androgen levels in aging males with improvements in body composition and sexual function. J Clin Endocrinol Metab 2003; 88: 2673-2681.

9 McNicholas TA, Dean JD, Mulder H, et al. A novel testosterone gel formulation normalizes androgen levels in hypogonadal men, with improvements in body composition and sexual function. BJU Int 2003; 91: 69-74.

10 Swerdloff RS, Wang C, Cunningham G, et al. Long-term pharmacokinetics of transdermal testosterone gel in hypogonadal men. J Clin Endocrinol Metab 2000; 85: 4500-4510.

11 Wang C, Berman N, Longstreth JA, et al. Pharmacokinetics of transdermal testosterone gel in hypogonadal men: application of gel at one site versus four sites: a General Clinical Research Center Study. J Clin Endocrinol Metab 2000; 85: 964-969.

12 Handelsman DJ, Liu PY. Klinefelter's syndrome a microcosm of male reproductive health. J Clin Endocrinol Metab 2006; 91: 1220-1222.

13 Herlihy AS, Halliday JL, Cock ML, McLachlan RI. The prevalence and diagnosis rates of Klinefelter syndrome: an Australian comparison. Med J Aust 2011; 194: 24-28.

14 Liverman CT, Blazer DG, editors. Testosterone and aging: clinical research directions. Washington, DC: The National Academies Press, 2004. http:// www.nap.edu/catalog.php?record_id=10852 (accessed Feb 2012).
15 Conway AJ, Handelsman DJ, Lording DW, et al; Endocrine Society of Australia. Use, misuse and abuse of androgens. The Endocrine Society of Australia consensus guidelines for androgen prescribing. Med J Aust 2000; 172: 220-224.

16 Bhasin S, Cunningham GR, Hayes FJ, et al. Testosterone therapy in adult men with androgen deficiency syndromes: an endocrine society clinical practice guideline. J Clin Endocrinol Metab 2006; 91: 1995-2010.

17 Nieschlag E, Swerdloff R, Behre HM, et al. Investigation, treatment and monitoring of lateonset hypogonadism in males: ISA, ISSAM, and EAU recommendations. Int J Androl 2005; 28: $125-127$.

18 Bhasin S, Cunningham GR, Hayes FJ, et al; Task Force, Endocrine Society. Testosterone therapy in men with androgen deficiency syndromes: an Endocrine Society clinical practice guideline. J Clin Endocrinol Metab 2010; 95: 2536-2559.

19 Wang C, Nieschlag E, Swerdloff R, et al. Investigation, treatment, and monitoring of lateonset hypogonadism in males: ISA, ISSAM, EAU, EAA, and ASA recommendations. J Androl 2009; 30: 1-9.

20 Wu FC, Tajar A, Beynon JM, et al; EMAS Group. Identification of late-onset hypogonadism in middle-aged and elderly men. NEngl J Med 2010; 363: 123-135.

21 Handelsman DJ. An old emperor finds new clothing: rejuvenation in our time. Asian J Androl 2011; 13: 125-129.

22 Basaria S, Coviello AD, Travison TG, et al. Adverse events associated with testosterone administration. NEngl J Med 2010; 363: 109-122.

23 Shabsigh R. Testosterone therapy in erectile dysfunction. Aging Male 2004; 7: 312-318.

24 Buvat J, Lemaire A. Endocrine screening in 1,022 men with erectile dysfunction: clinical significance and cost-effective strategy. J Urol 1997; 158: 1764-1767.

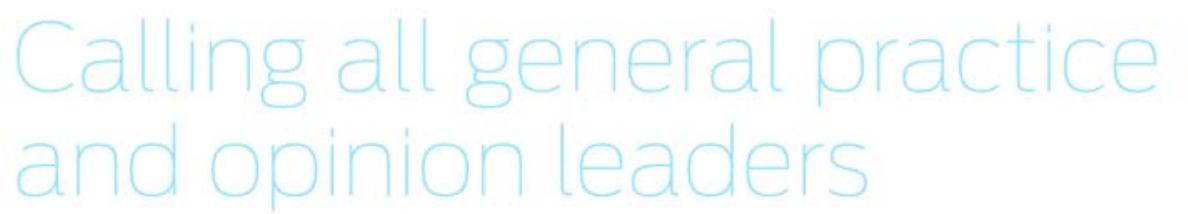

The MJA is open for business all year round. Rather than our yearly GP-themed issue, we are seeking to publish material relevant to general practice throughout the year.

\section{We want to host your best research, and to publish relevant comment on issues affecting general practice as they arise.}

Our call comes with a promise to prioritise excellent research, and to smooth the path to publication.

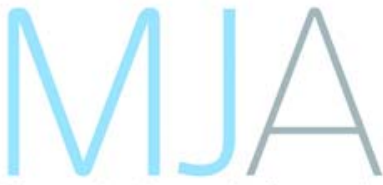

The Medical Journal of Australia
See our instructions to authors for submission guidelines http://www.mja.com.au/public/information/instruc.html 